\title{
Contribution of main culm and tillers to grain yield of durum wheat: Influence of sowing date and plant traits
}

\author{
Iduna Arduini, ${ }^{1}$ Elisa Pellegrino, ${ }^{2}$ Laura Ercoli ${ }^{2}$ \\ ${ }^{1}$ Department of Agriculture, Food and Environment, University of Pisa; ${ }^{2}$ Scuola Superiore Sant'Anna, Pisa, \\ Italy
}

\begin{abstract}
The question of whether tillers are a burden or a resource in durum wheat is of concern in the variable Mediterranean climates. The contribution of tillers to grain yield was investigated in commercial cultivars differing in time to anthesis, tillering and spike size, in response to three sowing dates:mid-autumn (recommended), winter, and early spring. The thermal time of phenological phases was calculated, and yield-components and floret production were analysed separately in main culm and tillers. Tiller spikes showed higher spikelet abortion coupled to lower spikelet fertility and mean kernel weight, so that grain yield was 40-60\% lower than in main culm spikes. Despite this, tillers contributed 35 to $50 \%$ to plant yield. The sowing date affected tiller number rather than one tiller yield. In winter sowings (December), lower main culm yield was fully compensated by increased tiller yield, whereas shifts of sowing date to early spring (February) reduced tillering, which caused a yield loss ranging from 12 to $20 \%$. Cultivars differed in one tiller yield rather than in tiller number, and higher grain yield of tillers was primarily due to increased grain recovery. A more equal partitioning of resources within main culm and tillers corresponded to better yield stability across sowing dates. Starting from this, we suggest that early anthesis, a long stem elongation phase, a high primordium initiation-rate and small spikes, could be positive traits for durum wheat yield stability in changing environ-
\end{abstract}

Correspondence: Iduna Arduini, Department of Agriculture, Food and Environment, University of Pisa, via del Borghetto 80, 56124 Pisa, Italy.

Tel.: +39.050.2218902

E-mail: iduna.arduini@unipi.it

Key words: Floret; genotype; grain recovery; spikelet; Triticum turgidum L. ssp. durum.

Received for publication: 26 September 2017.

Revision received: 2 March 2018.

Accepted for publication: 4 March 2018.

(C) Copyright I. Arduini et al., 2018

Licensee PAGEPress, Italy

Italian Journal of Agronomy 2018; 13:1115

doi:10.4081/ija.2018.1115

This article is distributed under the terms of the Creative Commons Attribution Noncommercial License (by-nc 4.0) which permits any noncommercial use, distribution, and reproduction in any medium, provided the original author(s) and source are credited. ments, since they allow plants directing more time and resources to floret production and grain filling both in main culm and tiller spikes. From a methodological point of view, our results show that the number of fertile florets per spike is highly correlated with the average floret number of five given spikelets.

\section{Introduction}

Wheat plants are formed by one main culm and a number of tillers varying from null to several tenths, depending on cultivar and environmental conditions. Grain yield of wheat crops is a quantitative trait determined by the product of three principal components: spike number per plant, or unit surface, mean kernel weight and kernel number per spike. Moreover, the last is a complex component resulting from the product of the number of spikelets per spike and the number of kernels per spikelet, and both these sub-components depend on their initiation and abortion rates, which occur at different stages during the crop cycle. Distinct components may compete or compensate and yield gain can be obtained by selecting for one or the other (Rharrabti et al., 2010; Ferrante et al., 2012; Slafer et al., 2014). The most outstanding success of past wheat breeding was to increase grain number per unit surface, which was primary obtained by increasing kernel number per spike, whereas the number of fertile tillers per plant was even reduced in order to uniform the achievement of maturity and reduce within plant competition (De Vita et al., 2007; Uzik and Zofajova, 2007; Fischer, 2016). In Italy and Spain, however, the genetic improvement of durum wheat in the last century increased both the number of grains per spike and the number of fertile tillers, despite the two yield components directly compete for assimilates (Brdar et al., 2008; Subira et al., 2015). This is because in Mediterranean semiarid environments, characterized by variable and unpredictable climatic conditions, high tillering may compensate for the poor crop establishment caused by late drought or early frost (Acevedo et al., 2002; Elhani et al., 2007). In addition, Dreccer et al. (2013) reported that tillers assist in competing against weeds, and, according to Spink et al. (2000), the production of more fertile tillers per plant can be a strategy to reduce seed costs.

Tiller number is the yield component with the highest plasticity (Slafer et al., 2014). Nevertheless, the genetic control of tiller production and the potential of tillers in wheat yield optimization have not been fully elucidated (Xie et al., 2016). According to Dreccer et al. (2013), low tillering wheat lines accumulate more water-soluble carbohydrates in stems, which leads to a higher grain number per spike and heavier kernels, though to only minimal yield increase. Artificial detillered plants and tin mutants have obtained a higher grain yield, which was associated with longer spikes and higher spikelet fertility (Kebrom et al., 2012; Hendriks 
et al., 2016). On the opposite, Xie et al. (2016) found that more fertile tillers per plant did not affect the yield of individual shoots and increased yield, and it was also reported that detillered plants yielded more in greenhouse conditions, but not in the field (Guo and Schnurbusch, 2015). In general, free-tillering was found detrimental in unfavourable environmental conditions (Mitchell et al., 2013; Hendriks et al., 2016), but was considered essential to take advantage of favourable conditions (Sadras and Rebetzke, 2013; Slafer et al., 2014). However, Elhani et al. (2007) reported that tillers contributed to grain yield more than the main culm in rainfed durum wheat. Therefore, to find an association between distinct morpho-phenological traits of wheat genotypes and the tiller contribution to yield in response to environmental conditions could be of help in selecting for those traits that are more adapt to changing environments.

Durum wheat (Triticum turgidum L. var. durum) is a staple cereal crop in the Mediterranean basin, where it is cultivated under rainfed conditions from autumn to early summer. Shifts from the recommended sowing dates are often necessary because soils are either too dry or too waterlogged, and these events are predicted to become more frequent in the near future (Bassu et al., 2009; Trnka et al., 2014). Wheat yield components are differently sensitive to delays in sowing date, and a Cultivar $\mathrm{x}$ Environment interaction exists (Subira et al., 2015). In general, late planting reduces grain yield (Inagaki et al., 2007; Arduini et al., 2009; Kumar et al., 2016), primarily because it shortens the period from emergence to anthesis, thus reducing the time for tiller and spike development (Whitechurch et al., 2007; Fischer, 2016). However, both lower (Akhtar et al., 2012) and higher (Arduini et al., 2009) numbers of spikes per unit surface were found in delayed sowings: the former due to reduced emergence in winter and to a shorter vegetative phase (Mahdi et al., 1999; Dreccer et al., 2013), the latter due to enhanced tiller growth rate at higher temperatures and longer day lengths (Kebrom et al., 2012). Yield losses in delayed sowings are generally associated with a lower kernel number per spike (Bassu et al., 2010; Kumar et al., 2016), but there is no agreement on whether the most affected determinant is the number of spikelets or the spikelet fertility (Li et al., 2001; Fischer, 2008; Arduini et al., 2009; González-Navarro et al., 2015).

Elhani et al. (2007) reported that environmental conditions influenced the determination of yield components differently in the two spike types, but, to the best of our knowledge, the effect of sowing date on spike yield components has never been analysed separately in the main culm and tiller spikes. In addition, the response of distinct spikelets to delays in sowing has not been previously investigated, though it is known that floret production and grain recovery differ among spikelets according to their position within the spike (Álvaro et al., 2008; Bancal, 2009).

The aim of our research was thus to i) determine the contribution of main culm and tiller spikes to grain yield of durum wheat; ii) analyse the influence of sowing date on the determination of yield components and sub-components in the two spike types; and iii) highlight if spikelet position within the spike may influence spikelet fertility in response to sowing date. Hypothesizing that phenological and morphological traits influence the contribution of tillers to plant yield, investigations were carried out on four durum wheat cultivars differing in time to anthesis, tillering capacity and spike traits (Ercoli et al., 2014), which were sown at three dates between mid-autumn and early spring.

\section{Materials and methods}

\section{Site and experimental design}

A two-year experiment was carried out from 2011 to 2013 at the Research Station of the Department of Agriculture, Food and Environment (University of Pisa, Italy), which is located approximately $4 \mathrm{~km}$ away from the sea $\left(43^{\circ} 40^{\prime} \mathrm{N}, 10^{\circ} 19^{\prime} \mathrm{E}\right)$ and is $1 \mathrm{~m}$ above sea level. The climate of the area is hot-summer Mediterranean (Csa): the mean annual maximum and minimum daily air temperatures are $20.2^{\circ} \mathrm{C}$ and $9.5^{\circ} \mathrm{C}$, respectively, and the mean rainfall is $971 \mathrm{~mm}$ per year. For the period of the research, the minimum and maximum daily temperatures and daily rainfall were obtained from a weather station located at the experimental site.

In both years, experimental treatments consisted of three sowing dates and four cultivars of durum wheat (Triticum turgidum L. ssp. durum). Sowing dates were: November (mid-autumn, recommended sowing for central Italy), December (winter sowing) and February (early spring sowing). The tested cultivars were Claudio (Cl), Normanno (Nm), Saragolla (Sg) and Svevo (Sv), all semidwarf modern genotypes selected in Italy for good-quality pasta production (Ercoli et al., 2011). The cultivars Normanno and Svevo are promoted as good tillering types, whereas for Saragolla and Claudio no information on tillering is given. Other cultivar features are reported in Table 1.

Each year, treatments were arranged in a split-plot factorial design, with four replicates. Sowing dates were the main plots and cultivars the subplots.

\section{Experimental equipment and crop management}

Plants were grown outdoors in 29-L pots. The pots were made from polyvinyl chloride (PVC) tubes $(60 \mathrm{~cm}$ long by $25 \mathrm{~cm}$ diameter) fitted with a PVC base serving as a bottom. A 30-mm-diameter hole was drilled in the bottom of each pot and a 5-cm layer of drainage gravel was added before soil. Pots were filled with $30 \mathrm{~kg}$ of soil, the main characteristics of which were similar over the two years and were approximately $54.9 \%$ sand $(2-0.05 \mathrm{~mm}), 33.5 \%$ silt (0.05-0.002 mm), $11.6 \%$ clay $(<0.002 \mathrm{~mm}), 7.7 \mathrm{pH}, 0.7 \mathrm{~g} \mathrm{~kg}^{-1}$ total $\mathrm{N}$ (Kjeldahl method), $4.4 \mathrm{mg} \mathrm{kg}^{-1}$ available phosphorus (Olsen method) and $69.3 \mathrm{mgkg}^{-1}$ available potassium $\left(\mathrm{BaCl}_{2}\right.$-TEA method). Pots were placed side-by-side into growth boxes built with a reticular net in order to allow plants to form a relatively normal and uniformly distributed aerial canopy structure. Edge effects were avoided by supplement pots placed around those used for harvests. All pots were embedded in expanded clay and growth boxes

Table 1. Genetic background and year of release of wheat cultivars used in the research.

\begin{tabular}{llc} 
Cultivar & Genetic origin & Year of release \\
Claudio & Cimmyt35/Durango//LS193B/Grazia & 1998 \\
Normanno & Simeto/F22//L35 & 2002 \\
\hline Saragolla & Iride/LineaPSB 0114 & 2004 \\
Svevo & Linea Cimmyt/Zenit & 1996 \\
\hline
\end{tabular}


surrounded by polystyrene panels to reduce daily fluctuations in soil temperature.

Sowing dates were 9 and 19 November, 28 and 20 December, and 9 and 19 February, in the growing seasons 2011-2012 and 2012-2013, respectively. Pots were sown with 20 seeds, placed in two rows spaced $12.5 \mathrm{~cm}$. After emergence, the seedlings were thinned to ten plants per pot, corresponding to approximately 200 plants $\mathrm{m}^{-2}$. This density is low compared to that of $300-400$ plant $\mathrm{m}^{-2}$ conventionally applied in central Italy, but it was chosen to reduce inter-plant competition for tiller development. Due to pot arrangement, canopy density was slightly lower, approximately 160 plants $\mathrm{m}^{-2}$. As a whole, 96 pots per year were harvested: 48 were harvested at anthesis for the determination of floret number, and 48 at maturity for the determination of grain yield and its components.

Phosphorus and potassium were applied pre-planting as triple mineral phosphate and potassium sulphate, at rates of $100 \mathrm{~kg} \mathrm{ha}^{-1}$ of $\mathrm{P}_{2} \mathrm{O}_{5}$ and $\mathrm{K}_{2} \mathrm{O}$. Following the management techniques typically used (Ercoli et al., 2013), nitrogen was applied at a rate of $150 \mathrm{~kg}$ $\mathrm{ha}^{-1}$ and was split into three applications: at sowing as ammonium sulphate, at pseudo-stem erection and at first node detectable as urea, in the following proportions: $30-60-60 \mathrm{~kg} \mathrm{~N} \mathrm{ha}^{-1}$. Weed control was performed by hand hoeing and pots were watered near to field capacity throughout the growing season. As the pots were well drained, both limiting and excess water conditions were avoided and therefore the effects of the very different rainfall in the two years were minimized.

\section{Plant measurements}

Over the entire growth cycle, phenological stages were recorded following the Zadoks' scale (Zadoks et al., 1974), as were the time of reaching emergence, anthesis and maturity, as reported in Table 2. In each pot, stages were considered achieved when they were observed on more than $50 \%$ of the plants. To distinguish main culm from tillers, at the stage 3-leaves unfolded (stage 13) the $3^{\text {rd }}$ leaf blade of all plants was marked with a spot of black nail polish, andat the stage the $5^{\text {th }}$ leaf tip was visible (stage 14) a red wool-thread was tied around the sheath of the $4^{\text {th }}$ leaf. As low order leaves are hard to detect at maturity, at later stages the $5^{\text {th }}$ and the $7^{\text {th }}$ leaf blades were also marked with different coloured nail polish.

At anthesis, five main culm (MC) and five tiller (T) spikes per pot were randomly chosen and immediately analysed, or stored in a refrigerator for maximum $48 \mathrm{~h}$. The number of spikelets per spike was counted and classified as complete (with well-developed glumes and awns) and aborted (with very small glumes and awns missing or very short). The number of fertile florets was counted under a stereomicroscope (Leica Z16 APO) with a magnification up to $92 \mathrm{x}$ on five sample spikelets (two basal, two central, and the terminal spikelet), as shown in Figure 1. Florets were considered fertile when they had green anthers and a bifidum stigma (Álvaro et al., 2008).

At maturity, plants were harvested and separated into main culm, fertile tillers (bearing a spike) and sterile tillers. On each plant we determined the number of fertile and sterile tillers, the number of leaves formed on the main culm, and the number of complete and aborted spikelets of MC and T spikes. In addition, on five $\mathrm{MC}$ and five $\mathrm{T}$ spikes per pot, we counted the number of kernels on five spikelets where the position was the same as chosen for floret counts (Figure 1). Main culm and tiller spikes of each pot were separately threshed with a laboratory thresher and the grain yield and kernel numbers were determined for each spike type.

\section{Calculations}

The duration of phenological stages was expressed in thermal time, calculated as the sum of heat units measured in growing degree-days $(\mathrm{GDD})$, as GDD $=((\mathrm{Tmax}+\mathrm{Tmin}) / 2)-\mathrm{Tb}$. In the formula, Tmax and Tmin are the daily maximum and minimum air temperatures, and $\mathrm{Tb}$ is the base temperature below which no significant crop development occurs. If $\mathrm{Tmin}<\mathrm{Tb}$ then $\mathrm{Tmin}=\mathrm{Tb}$ was also incorporated into the equation. An upper threshold temperature (Tut), above which crop development is negatively affected, was also incorporated, i.e., if Tmax $>$ Tut then Tmax $=$ Tut (McMaster and Wilhelm, 1997). The utilized cardinal intervals were $0-25^{\circ} \mathrm{C}$ up to the stage the first node was detectable and $7-$ $30^{\circ} \mathrm{C}$ for the following phases (Porter and Gawith, 1999; Eshaghi et al., 2011).

The number of total primordia initiated on main culms was obtained as the sum of final leaves and total spikelets. Spikelet abortion rate was calculated as the percentage ratio of aborted and total (complete+aborted) spikelets. Mean kernel weight was calculated separately for $\mathrm{MC}$ and $\mathrm{T}$ spikes by dividing $\mathrm{MC}$ (or $\mathrm{T}$ ) grain yield per pot by the number of MC (or T) kernels per pot. The number of florets, or kernels, in basal and central spikelets was averaged for the two spikelets analysed for each position. Grain recovery was calculated for each position, as the percentage of the number of kernels per spikelet on the number of florets per spikelet.

Floret counts are laborious and time-consuming and must be carried out over a short time span, so it is more convenient to estimate the total number of florets within a spike from that of a few sample spikelets. Thus, in the first year of the research, we counted

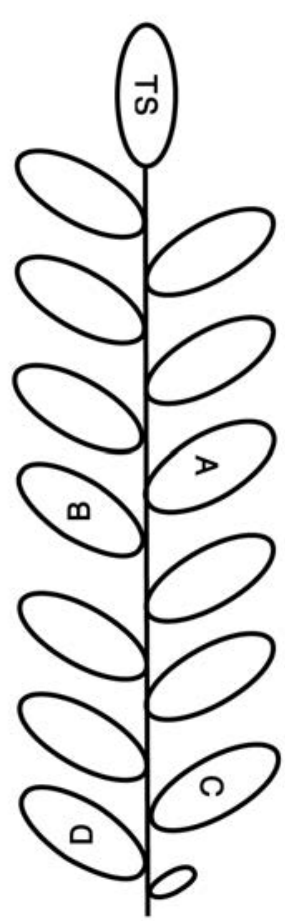

Figure 1. Position of spikelets utilised for floret counts: basal (C, D); central (A, B); terminal spikelet (TS). 
all fertile florets of one $\mathrm{MC}$ and one $\mathrm{T}$ spike per pot (96 in total) and plotted the obtained values against the average floret numbers of two basal, two central and the terminal spikelet of the same spikes, multiplied by the number of complete spikelets. We found that counted and estimated values were closely related when the average of two basal, two central and the terminal spikelet were used (Figure 2). In addition, we also found a significant relationship between the counted kernels per spike and the average kernel number of two basal, two central and the terminal spikelet multiplied by the number of complete spikelets (Figure 2). These findings allowed usto estimate the number of fertile florets per spike by multiplying the average number of florets of the five chosen spikelets per the number of complete spikelets per spike, and then calculating grain recovery on a spike basis.

\section{Statistical analysis}

Results were subjected to analysis of variance (Tables 3 and 4). The experimental design was a split-split-plot with four replicates: years were located as main plots, sowing dates as subplots and cultivars as sub-subplots. To assess if the number of florets and kernels per spikelet and grain recovery were affected by spikelet posi- tion within the spike, we arranged these data in a split-split-splitplot experimental design. Years were located as main plots, sowing dates as subplots, cultivars as sub-subplots, and spikelet positions as sub-sub-subplots. Percentage data were arcsin transformed before analysis. Significantly different means were separated at a 0.05 probability level by Tukey's test (Steel et al., 1997).

\section{Results}

\section{Climate}

The mean temperature of the entire wheat growing season (November-July) was quite similar in 2011-12 and 2012-13, at 11.6 and $12^{\circ} \mathrm{C}$, respectively. However, in the first season the average minimum temperature was lower $\left(4.9\right.$ vs $\left.6.9^{\circ} \mathrm{C}\right)$ and the maximum temperature higher $\left(18.3\right.$ vs $\left.17.1^{\circ} \mathrm{C}\right)$ than in the second (Figure 3). Rainfall differed more than twofold (499 vs $1155 \mathrm{~mm}$ ) in the two growing seasons. Differences were greatest in winter, with a cumulative rainfall of $70 \mathrm{~mm}$ in 2011-2012, and $596 \mathrm{~mm}$ in

Table 2. Time (days after sowing) to emergence, anthesis and maturity, as affected by sowing date and cultivar, in the growing seasons 2011-2012 and 2012-2013.

\begin{tabular}{lccccccc} 
Stage & Cultivar & 09-Nov 2011 & 19-Nov 2012 & 28-Dec 2011 & 20-Dec 2012 & 09-Feb 2012 & 19-Feb2013 \\
Emergence & & 13 & 14 & 32 & 36 & 20 & 19 \\
Anthesis & Claudio & 172 & 165 & 170 & 134 & 138 & 97 \\
& Normanno & 180 & 162 & 134 & 139 & 97 & 90 \\
& Saragolla & 169 & 162 & 131 & 134 & 93 & 95 \\
& Svevo & 169 & 218 & 186 & 190 & 146 & 140 \\
\hline Maturity & & 224 & &
\end{tabular}

Table 3. Results of ANOVA for the experimental design split-split-plot Year $\times$ Sowing date $\times$ Cultivar.

\begin{tabular}{|c|c|c|c|c|c|c|c|c|c|c|c|}
\hline Treatments & $\begin{array}{l}\text { Grain } \\
\text { yield } \\
\text { plant }^{-1} \text { ) }\end{array}$ & & $\begin{array}{l}\text { Leaves } \\
\text { (n) }\end{array}$ & $\begin{array}{l}\text { Total } \\
\text { imordia } \\
\text { (n) }\end{array}$ & $\begin{array}{l}\text { Grain } \\
\text { yield } \\
\left(\text { g spike }{ }^{-1}\right)\end{array}$ & $\begin{array}{l}\text { Main culm } \\
\text { Kernels } \\
\text { (n spike }{ }^{-1} \text { ) }\end{array}$ & $\begin{array}{l}\text { MKW } \\
\text { (g) }\end{array}$ & $\begin{array}{l}\text { Complete } \\
\text { spikelets } \\
\text { (n spike-1) }\end{array}$ & $\begin{array}{l}\text { Initiated } \\
\text { spikelets } \\
\text { (n spike-1) }\end{array}$ & $\begin{array}{l}\text { Spikelet } \\
\text { abortion } \\
(\%)\end{array}$ & $\begin{array}{c}\text { Fertile } \\
\text { florets } \\
\left.\text { (n spike }{ }^{-1}\right)\end{array}$ \\
\hline Year (Y) & $*$ & & n.s. & n.s. & n.s. & n.s. & n.s. & n.s. & n.s. & n.s. & n.s. \\
\hline Sowing date (S) & $*$ & & $*$ & $*$ & $*$ & $*$ & $*$ & $*$ & $*$ & $*$ & n.s. \\
\hline $\mathrm{Y} \times \mathrm{S}$ & n.s. & & n.s. & n.s. & n.s. & n.s. & n.s. & n.s. & n.s. & n.s. & n.s. \\
\hline Cultivar (C) & $*$ & & $*$ & $*$ & $*$ & n.s. & $*$ & $*$ & $*$ & $*$ & $*$ \\
\hline $\mathrm{Y} \times \mathrm{C}$ & n.s. & & n.s. & n.s. & n.s. & n.s. & n.s. & n.s. & n.s. & n.s. & n.s. \\
\hline $\mathrm{S} \times \mathrm{C}$ & $*$ & & n.s. & n.s. & n.s. & n.s. & n.s. & n.s. & n.s. & n.s. & n.s. \\
\hline $\mathrm{Y} \times \mathrm{S} \times \mathrm{C}$ & n.s. & & n.s. & n.s. & n.s. & n.s. & n.s. & n.s. & n.s. & n.s. & n.s. \\
\hline (n & $\begin{array}{l}\text { Tiller } \\
\text { plant }\end{array}$ & $\begin{array}{l}\text { Spikes } \\
\text { (n plant }{ }^{-1} \text { ) }\end{array}$ & $\begin{array}{l}\text { Cumulative } \\
\text { grain yield } \\
\left(\text { g plant }{ }^{-1}\right)\end{array}$ & $\begin{array}{l}\text { CIY } \\
(\%)\end{array}$ & $\begin{array}{c}\text { Grain } \\
\text { yield } \\
\left.\text { (g spike }^{-1}\right)\end{array}$ & $\begin{array}{c}\text { Kernels } \\
(\text { n spike-1) }\end{array}$ & $\begin{array}{l}\text { MKW } \\
\text { (g) }\end{array}$ & $\begin{array}{c}\text { Complete } \\
\text { spikelets } \\
\text { (n spike-1) }\end{array}$ & $\begin{array}{l}\text { Initiated } \\
\text { spikelets } \\
\text { (n spike-1) }\end{array}$ & $\begin{array}{l}\text { Spikelet } \\
\text { abortion } \\
\left(n \text { spike }^{-1}\right)\end{array}$ & $\begin{array}{c}\text { Fertile } \\
\text { florets } \\
\left(n \text { spike }^{-1}\right)\end{array}$ \\
\hline Year $(Y)$ & n.s. & n.s. & $*$ & $*$ & n.s. & n.s. & n.s. & n.s. & n.s. & n.s. & n.s. \\
\hline Sowing date (S) & $*$ & $*$ & $*$ & $*$ & n.s. & n.s. & $*$ & $*$ & $*$ & $*$ & $*$ \\
\hline $\mathrm{Y} \times \mathrm{S}$ & n.s. & n.s. & n.s. & n.s. & n.s. & n.s. & n.s. & n.s. & n.s. & n.s. & n.s. \\
\hline Cultivar (C) & $*$ & n.s. & $*$ & $*$ & $*$ & $*$ & $*$ & $*$ & $*$ & $*$ & $*$ \\
\hline $\mathrm{Y} \times \mathrm{C}$ & n.s. & n.s. & n.s. & n.s. & n.s. & n.s. & n.s. & n.s. & n.s. & n.s. & n.s. \\
\hline $\mathrm{S} \times \mathrm{C}$ & n.s. & n.s. & n.s. & n.s. & n.s. & n.s. & n.s. & n.s. & n.s. & n.s. & n.s. \\
\hline $\mathrm{Y} \times \mathrm{S} \times \mathrm{C}$ & n.s. & n.s. & n.s. & n.s. & n.s. & n.s. & n.s. & n.s. & n.s. & n.s. & n.s. \\
\hline
\end{tabular}


2012-2013 (Figure 3). Around anthesis and during grain-filling, conversely, rainfall was $83 \mathrm{~mm}$ higher in the dryer growing season.

\section{Phenology}

In the warmer growing season of 2012-2013, growth cycles were 4-6 days shorter than in 2011-2012, whereas anthesis occurred approximately one week earlier in November and February sowings, but four days later in December, probably because of slower emergence (Table 2). Time to anthesis was reduced with the delay of sowing, by approximately 40 days in December and by 77 days in February, so that the length of the entire growth cycle decreased from approximately 221 days in November to 188 in December and

Table 4. Results of ANOVA for the experimental design split-split-split-plot Year $\times$ Sowing date $\times$ Cultivar $\times$ Spikelet position.

\begin{tabular}{|c|c|c|c|c|c|c|}
\hline Treatments & $\begin{array}{l}\text { Fertile florets } \\
\text { (n spikelet }{ }^{-1} \text { ) }\end{array}$ & $\begin{array}{l}\text { Main culm } \\
\text { Kernels } \\
\text { (n spikelet }{ }^{-1} \text { ) }\end{array}$ & $\begin{array}{c}\text { Grain recovery per } \\
\text { spikelet (\%) }\end{array}$ & $\begin{array}{l}\text { Fertile florets } \\
\text { (n spikelet }{ }^{-1} \text { ) }\end{array}$ & $\begin{array}{c}\text { Tillers } \\
\text { Kernels } \\
\text { (n spikelet }{ }^{-1} \text { ) }\end{array}$ & $\begin{array}{c}\text { Grain recovery per } \\
\text { spikelet }(\%)\end{array}$ \\
\hline Year (Y) & n.s. & n.s. & n.s. & n.s. & n.s. & n.s. \\
\hline Sowing date (S) & $*$ & n.s. & $*$ & n.s. & n.s. & n.s. \\
\hline $\mathrm{Y} \times \mathrm{S}$ & n.s. & n.s. & n.s. & n.s. & n.s. & n.s. \\
\hline Cultivar (C) & $*$ & $*$ & $*$ & n.s. & $*$ & $*$ \\
\hline $\mathrm{Y} \times \mathrm{C}$ & n.s. & n.s. & n.s. & n.s. & n.s. & n.s. \\
\hline $\mathrm{S} \times \mathrm{C}$ & n.s. & n.s. & n.s. & n.s. & n.s. & n.s. \\
\hline $\mathrm{Y} \times \mathrm{S} \times \mathrm{C}$ & n.s. & n.s. & n.s. & n.s. & n.s. & n.s. \\
\hline Spikelet position (P) & $*$ & $*$ & $*$ & $*$ & $*$ & $*$ \\
\hline $\mathrm{Y} \times \mathrm{P}$ & n.s. & n.s. & n.s. & n.s. & n.s. & n.s. \\
\hline $\mathrm{S} \times \mathrm{P}$ & n.s. & n.s. & n.s. & n.s. & n.s. & n.s. \\
\hline $\mathrm{C} \times \mathrm{P}$ & $*$ & n.s. & n.s. & $*$ & n.s. & n.s. \\
\hline $\mathrm{Y} \times \mathrm{S} \times \mathrm{P}$ & n.s. & n.s. & n.s. & n.s. & n.s. & n.s. \\
\hline $\mathrm{Y} \times \mathrm{C} \times \mathrm{P}$ & n.s. & n.s. & n.s. & n.s. & n.s. & n.s. \\
\hline $\mathrm{S} \times \mathrm{C} \times \mathrm{P}$ & n.s. & n.s. & n.s. & n.s. & n.s. & n.s. \\
\hline $\mathrm{Y} \times \mathrm{S} \times \mathrm{C} \times \mathrm{P}$ & n.s. & n.s. & n.s. & n.s. & n.s. & n.s. \\
\hline
\end{tabular}
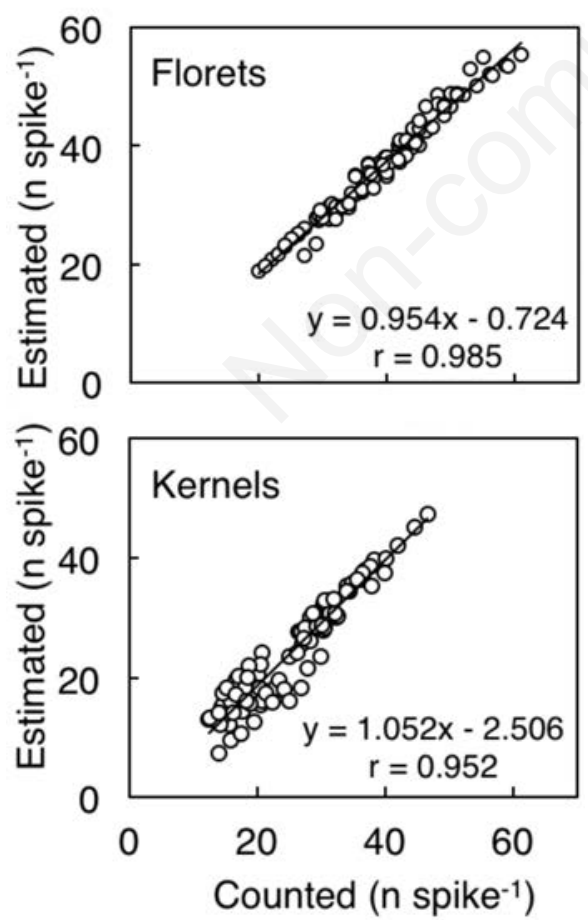

Figure 2. Relationships between the numbers of florets, or kernels, per spike counted and estimated as the mean value of five spikelets per spike (two basal, two central and the terminal spikelet) multiplied by the number of complete spikeletsper spike ( $n=96)$.
$2011-2012$
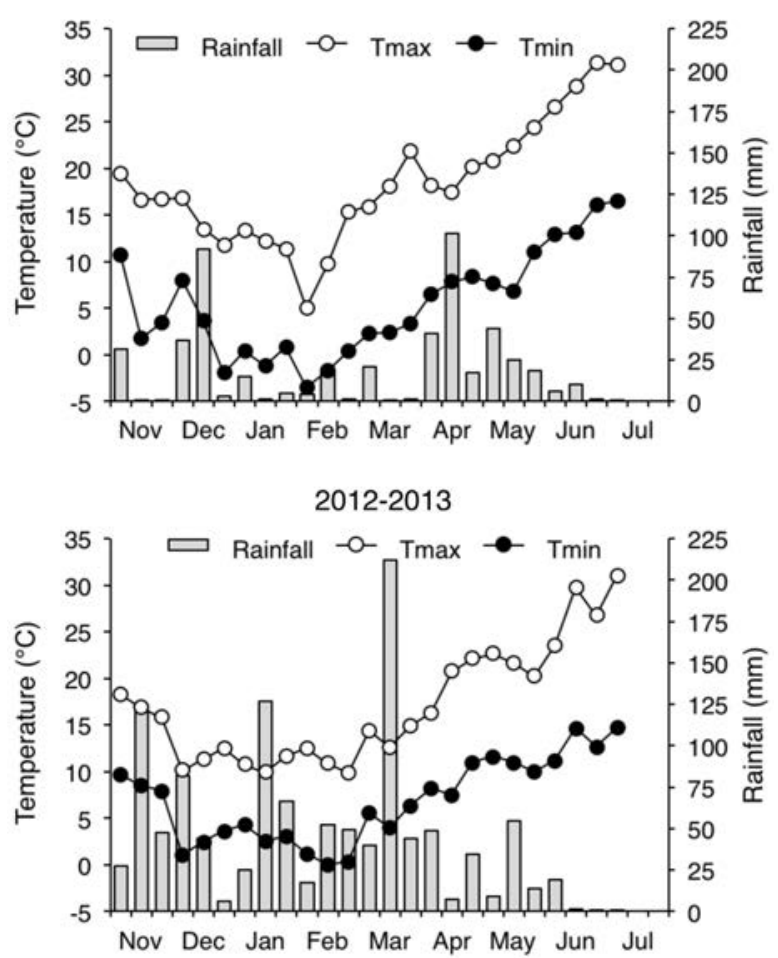

Figure 3. Decadic maximum and minimum temperatures and rainfall over the durum wheat growing seasons 2011-12 and 2012-13. 
143 in February. In both years and all sowings, Saragolla and Svevo reached anthesis earlier than Claudio and Normanno, whereas maturity was achieved by all cultivars on the same date.

The thermal time of plant phases was differently affected by the delay of sowing. In November and February sowings plants needed approximately $130^{\circ} \mathrm{Cd}$ to complete emergence, whereas they required $215^{\circ} \mathrm{Cd}$ in December (data not shown). The length of the vegetative phase (emergence- $1^{\text {st }}$ node detectable) decreased up to $48 \%$ from November to February, with the highest reduction between November and December (Figure 4A). The duration of stem elongation ( $1^{\text {st }}$ node detectable-anthesis) was less affected by sowing date and patterns differed slightly among cultivars (Figure 4B). Finally, the grain-filling phase (anthesis-maturity) increased between November and December and then did not change further (Figure 4C). Cultivars did not differ in the time to emergence and differences in the length of following phases were more appreciable in November than in later sowings. The thermal time of the vegetative phase decreased in the order Normanno $>$ Claudio $>$ Saragolla $>$ Svevo, with an overall $13 \%$ decrease; the stem elongation phase was $18 \%$ longer in Normanno and Svevo compared to Claudio and Saragolla, and the grain filling phase was $14 \%$ shorter in Normanno (Figure 4). As a result the thermal time to anthesis equalled in the cultivars Saragolla and Svevo and was from 5 to $12 \%$ longer in the cultivars Claudio and Normanno, respectively.

\section{Grain yield of plants}

Analysis of variance highlighted a significant year mean effect for the grain yield per plant, the cumulative grain yield of tillers, and the contribution of tillers to yield (Table 3). The interactions with year were never significant, and those between sowing date and cultivar were only found to be significant for grain yield per plant. Accordingly, all data were presented as means of the two growing seasons and, except for grain yield per plant, they were presented as sowing date and cultivar mean effects.

Averaged over years, in all cultivars grain yield per plant did not change significantly between November and December sowings and decreased in February, but the decrease was by $12 \%$ in Svevo and by approximately $20 \%$ in the other cultivars (Figure 5 ). The cultivar Claudio yielded $8 \%$ less than the others in November. Averaged over seeding dates and cultivars, grain yield was $16 \%$

Table 5. Number of tillers and tiller spikes per plant, tiller yield, and contribution of tillers to grain yield per plant (CTY), as affected by the growing season, sowing date, and cultivar mean effects.

\begin{tabular}{|c|c|c|c|c|}
\hline Treatment & $\begin{array}{c}\text { Tillers } \\
\left(\text { n plant }^{-1}\right)\end{array}$ & $\begin{array}{l}\text { T spikes } \\
(\mathrm{n} \text { plant } \\
\text { (1) }\end{array}$ & $\begin{array}{l}\text { T yield } \\
\left(\text { g plant }^{-1}\right)\end{array}$ & $\begin{array}{l}\text { CTY } \\
(\%)\end{array}$ \\
\hline \multicolumn{5}{|l|}{ Growing season } \\
\hline 2011-2012 & $4.2^{\mathrm{a}}$ & $1.8^{\mathrm{a}}$ & $1.4^{\mathrm{a}}$ & $46.1^{\mathrm{a}}$ \\
\hline 2012-2013 & $4.1^{\mathrm{a}}$ & $1.4^{\mathrm{a}}$ & $1.0^{\mathrm{b}}$ & $39.0^{\mathrm{b}}$ \\
\hline \multicolumn{5}{|l|}{ Sowing date } \\
\hline November & $4.3^{\mathrm{a}}$ & $1.8^{\mathrm{a}}$ & $1.3^{\mathrm{a}}$ & $44.4^{\mathrm{a}}$ \\
\hline December & $4.7^{\mathrm{a}}$ & $2.0^{\mathrm{a}}$ & $1.5^{\mathrm{a}}$ & $49.9^{\mathrm{a}}$ \\
\hline February & $3.6^{\mathrm{b}}$ & $1.3^{b}$ & $0.9^{\mathrm{b}}$ & $35.5^{\mathrm{b}}$ \\
\hline \multicolumn{5}{|l|}{ Cultivar } \\
\hline Claudio & $4.4^{\mathrm{ab}}$ & $1.9^{\mathrm{a}}$ & $1.2^{\mathrm{b}}$ & $41.7^{\mathrm{b}}$ \\
\hline Normanno & $3.8^{\mathrm{b}}$ & $1.7^{\mathrm{a}}$ & $1.2^{\mathrm{b}}$ & $41.4^{b}$ \\
\hline Saragolla & $4.9^{\mathrm{a}}$ & $1.5^{\mathrm{a}}$ & $1.2^{\mathrm{b}}$ & $40.7^{b}$ \\
\hline Svevo & $3.6^{\mathrm{b}}$ & $1.7^{\mathrm{a}}$ & $1.5^{\mathrm{a}}$ & $49.2^{\mathrm{a}}$ \\
\hline
\end{tabular}

Within each block, values followed by different letters are significantly different $(\mathrm{P}<0.05)$. lower in the growing season 2012-2013 (2.6 vs $3.1 \mathrm{~g} \mathrm{plant}^{-1}$ ), which was a consequence of the lower contribution of tillers to plant yield (Table 5). Tiller number, fertility and yield slightly and not significantly increased with the delay of sowing from November to December, whereas a further delay to February sig-
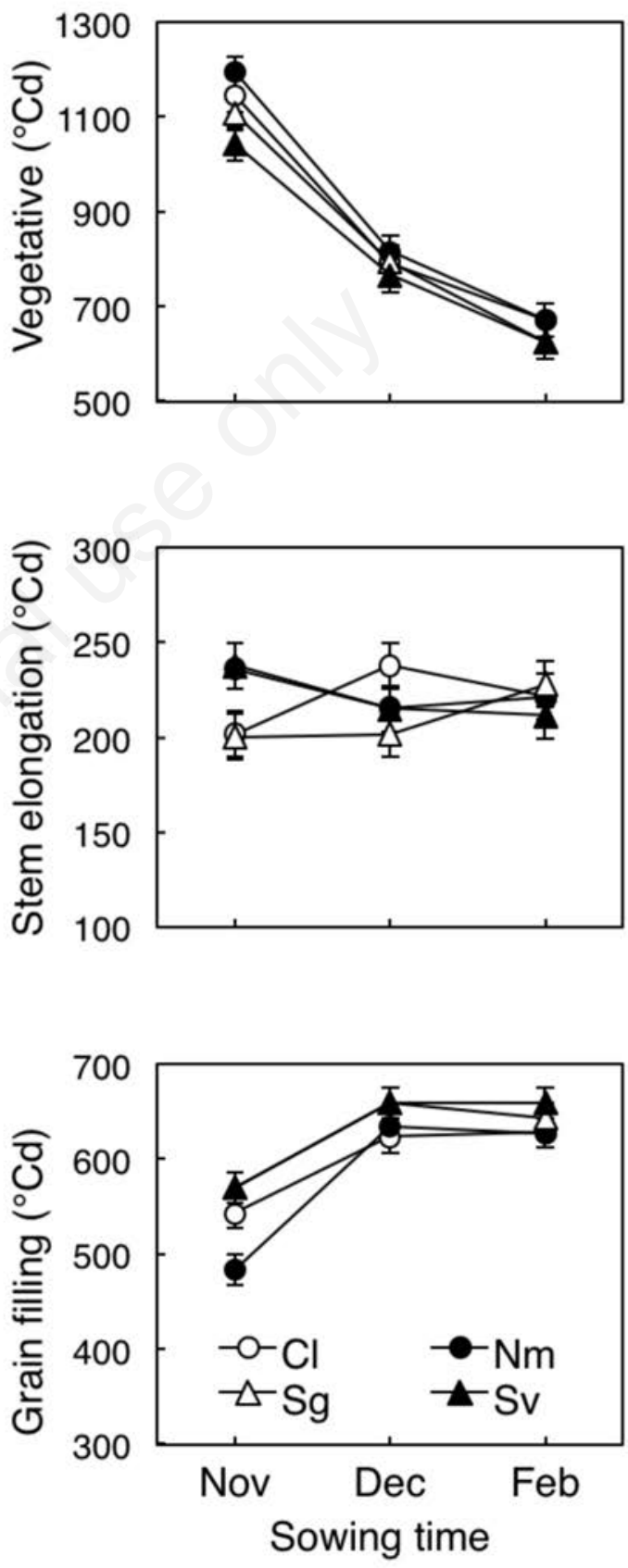

Figure 4. Thermal times of the vegetative (emergence-1st node detectable, A), stem elongation ( $1^{\text {st }}$ node detectable-anthesis, $B$ ) and grain filling (anthesis-maturity, C) periods, as affected by sowing date and cultivar. $\mathrm{Cl}$, Claudio; $\mathrm{Nm}$, Normanno, $\mathrm{Sg}$, Saragolla; Sv, Svevo. Data are means of two years and four replicates $(n=8)$. Vertical bars represent honest significant difference at $\mathrm{P}<0.05$. 
nificantly decreased these parameters. Accordingly, the contribution of tillers to plant yield ranked in the order December $\geq$ November $>$ February (Table 5). Despite differences in tiller production, cultivars did not significantly differ in the number of tiller spikes. Conversely, the cumulative grain yield of tillers per plant was $25 \%$ higher in Svevo, which increased the contribution of tillers to plant yield by approximately eight percentage points.

\section{Grain yield and yield components of main culm and tiller spikes}

Sowing date only slightly affected the grain yield of MC spikes and did not affect that of $\mathrm{T}$ spikes (Table 6). Yield components responded differently to sowing date, with similar trends in $\mathrm{MC}$ and $\mathrm{T}$ spikes. The mean kernel weight was lowest in November, whereas the number of kernels per spike was highest. The number of complete spikelets per spike progressively decreased with the delay of sowing, whereas the number of kernels per spikelet was unaffected.

Grain yield per spike significantly differed among cultivars, with different rankings for MC and T (Table 6). The former yielded more in Normanno and Saragolla, whereas the latter in Svevo and Saragolla. Accordingly, the grain yield of MC spikes was always markedly higher than that of $\mathrm{T}$ spikes, but the increase was by $67 \%, 111 \%, 139 \%$ and $159 \%$, in Svevo, Saragolla, Normanno and Claudio, respectively. The mean kernel weight was significantly lower in the cultivar Normanno in both spike types, while the highest values were recorded in Claudio. The number of kernels per spike did not differ among cultivars in $\mathrm{MC}$ and was approximately five kernels lower in Claudio in T. In both spike types, the number of complete spikelets ranked in the order Saragolla $>$ Normanno $>$ Claudio $>$ Svevo, with significant higher values in Saragolla compared to Claudio and Svevo. Finally, the number of kernels per spikelet was lower in Saragolla in MC spikes and higher in Svevo in T spikes.
Despite the above differences among cultivars and independently of sowing date, in MC and T spikes, grain yield per spike was positively and significantly correlated with the number of kernels per spike, which in turn was correlated with the number of kernels per spikelet (Figure 6). Otherwise, no relationships were found for grain yield per spike, or kernels per spike, with other yield components and sub-components (data not shown).

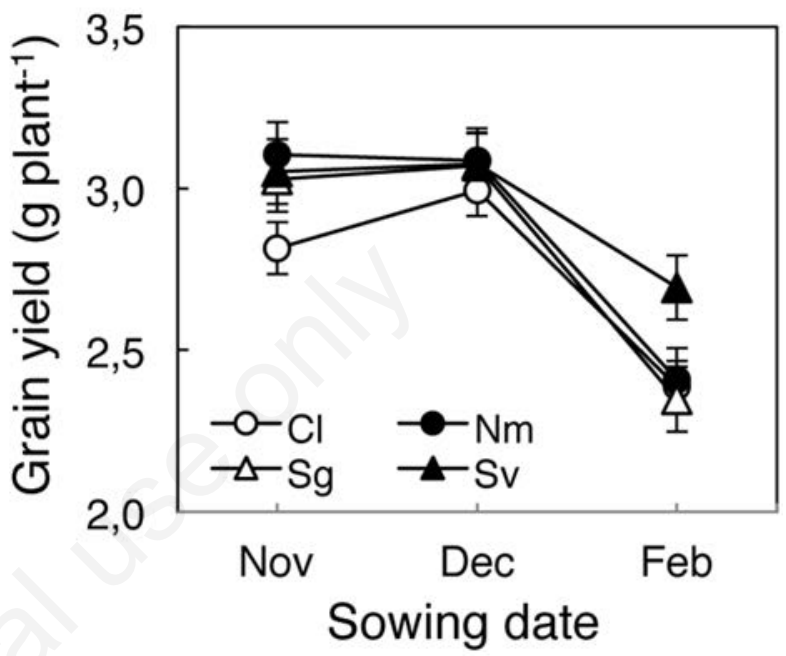

Figure 5. Grain yield per plant, as affected by sowing date and cultivar. Cl, Claudio; Nm, Normanno, Sg, Saragolla; Sv, Svevo. Data are means of two years and four replicates $(n=8)$. Vertical bars represent honest significant difference at $\mathbf{P}<0.05$.

Table 6. Grain yield and yield components of main culm and tiller spikes, as affected by the sowing date and cultivar mean effects.

\begin{tabular}{|c|c|c|c|c|c|}
\hline Treatment & $\begin{array}{l}\text { Grain yield } \\
\left(\text { g spike } \text { sp }^{-1}\right)\end{array}$ & $\begin{array}{c}\text { Mean kernel weight } \\
\text { (mg) }\end{array}$ & $\begin{array}{c}\text { Kernels } \\
\text { (n spike }{ }^{-1} \text { ) } \\
\text { Main culm spike }\end{array}$ & $\begin{array}{l}\text { Complete spikelets } \\
\text { (n spike }{ }^{-1} \text { ) }\end{array}$ & $\begin{array}{c}\text { Kernels } \\
\text { (n spikelet }{ }^{-1} \text { ) }\end{array}$ \\
\hline \multicolumn{6}{|l|}{ Sowing date } \\
\hline November & $1.7^{\mathrm{a}}$ & $46.1^{\mathrm{b}}$ & $36.4^{\mathrm{a}}$ & $16.5^{\mathrm{a}}$ & $2.2^{\mathrm{a}}$ \\
\hline December & $1.5^{b}$ & $51.1^{\mathrm{a}}$ & $30.0^{\mathrm{b}}$ & $14.7^{\mathrm{b}}$ & $2.1^{\mathrm{a}}$ \\
\hline February & $1.6^{\mathrm{ab}}$ & $51.3^{\mathrm{a}}$ & $30.6^{\mathrm{b}}$ & $13.5 \mathrm{c}$ & $2.3^{\mathrm{a}}$ \\
\hline \multicolumn{6}{|l|}{ Cultivar } \\
\hline Claudio & $1.6^{\mathrm{ab}}$ & $53.7^{\mathrm{a}}$ & $29.6^{\mathrm{a}}$ & $13.6^{\mathrm{b}}$ & $2.2^{\mathrm{a}}$ \\
\hline Normanno & $1.7^{\mathrm{a}}$ & $45.7^{\mathrm{b}}$ & $36.0^{\mathrm{a}}$ & $15.8^{a b}$ & $2.3^{\mathrm{a}}$ \\
\hline Saragolla & $1.7^{\mathrm{a}}$ & $50.4^{\mathrm{a}}$ & $33.2^{\mathrm{a}}$ & $17.2^{\mathrm{a}}$ & $1.9^{b}$ \\
\hline Svevo & $1.5^{b}$ & $48.2^{\mathrm{ab}}$ & $30.5^{\mathrm{a}}$ & $13.1^{\mathrm{b}}$ & $2.3^{\mathrm{a}}$ \\
\hline \multicolumn{6}{|l|}{ Tiller spike } \\
\hline \multicolumn{6}{|l|}{ Sowing date } \\
\hline November & $0.76^{\mathrm{a}}$ & $43.6^{\mathrm{b}}$ & $17.6^{\mathrm{a}}$ & $13.1^{\mathrm{a}}$ & $1.4^{\mathrm{a}}$ \\
\hline December & $0.76^{\mathrm{a}}$ & $46.3^{\mathrm{a}}$ & $16.4^{\mathrm{a}}$ & $11.6^{\mathrm{ab}}$ & $1.4^{\mathrm{a}}$ \\
\hline February & $0.70^{\mathrm{a}}$ & $46.2^{\mathrm{a}}$ & $14.9^{\mathrm{a}}$ & $10.3^{b}$ & $1.4^{\mathrm{a}}$ \\
\hline \multicolumn{6}{|l|}{ Cultivar } \\
\hline Claudio & $0.61^{\mathrm{b}}$ & $47.4^{\mathrm{a}}$ & $12.8^{\mathrm{b}}$ & $11.0^{b c}$ & $1.2^{\mathrm{b}}$ \\
\hline Normanno & $0.69^{\mathrm{b}}$ & $41.4^{\mathrm{b}}$ & $16.5^{\mathrm{a}}$ & $12.4^{\mathrm{ab}}$ & $1.4^{\mathrm{b}}$ \\
\hline Saragolla & $0.79^{\mathrm{a}}$ & $45.4^{\mathrm{a}}$ & $17.4^{\mathrm{a}}$ & $13.0^{\mathrm{a}}$ & $1.3^{b}$ \\
\hline Svevo & $0.87^{\mathrm{a}}$ & $47.2^{\mathrm{a}}$ & $18.5^{\mathrm{a}}$ & $10.2^{c}$ & $1.8^{\mathrm{a}}$ \\
\hline
\end{tabular}

Within each block, values followed by different letters are significantly different $(\mathrm{P}<0.05)$. 


\section{Primordia initiation and abortion}

The number of complete spikelets in a spike is a function of the number of spikelet primordia initiated by the culm apex and their abortion rate. Our results highlighted that the number of initiated spikelets was less than two units lower in T compared to MC, whereas the abortion rate was markedly higher in the former, at 13 vs 4\% (Table 7). The delay in sowing reduced both the initiation and the abortion of spikelets, so that the decrease in complete spikelets was lower than that in total spikelets, particularly in tillers (Tables 6 and 7). Averaged over sowing dates, the number of initiated spikelets was significantly higher in the cultivars Normanno and Saragolla, and the latter cultivar also showed the lowest abortion rate (Table 7).

The number of leaves formed on the main culm decreased progressively from November to February, averaged over cultivars (Table 8). Thus, the total leaf and spikelet primordial initiated on the main culm apex decreased by approximately five units, from 28.3 to 23 with the delay of sowing. Averaged over sowings, the number of MC leaves was significantly higher in Claudio and lower in Saragolla, while intermediate values were recorded in Normanno and Svevo. Accordingly, the total number of initiated MC primordia was significantly lower in Svevo compared with the other cultivars.

\section{Floret formation and grain recovery}

Analysis of variance highlighted that sowing date, cultivar and spikelet position affected floret number and grain recovery per spikelet, but no year effect was detected (Table 4). The only significant interaction was found between cultivar and spikelet position for the floret number.

The number of fertile florets per spikelet increased progressively with the delay of sowing, but the increment was significant only in MC between November and February (Table 7). In MC spikes, the number of fertile florets per spikelet did not differ significantly among cultivars in the basal spikelets, whereas it was approximately 0.5 florets lower in Claudio in the other positions (Figure 7). In T spikes, differences were found only in the terminal spikelet, with Svevo and Normanno showing approximately 2.1 florets and Claudio and Saragolla 1.6. The number of fertile florets per spikelet was always higher in MC than in T spikes and depended on spikelet position, decreasing significantly in the order central $>$ basal $\geq$ terminal in both spike types. On average, the number of
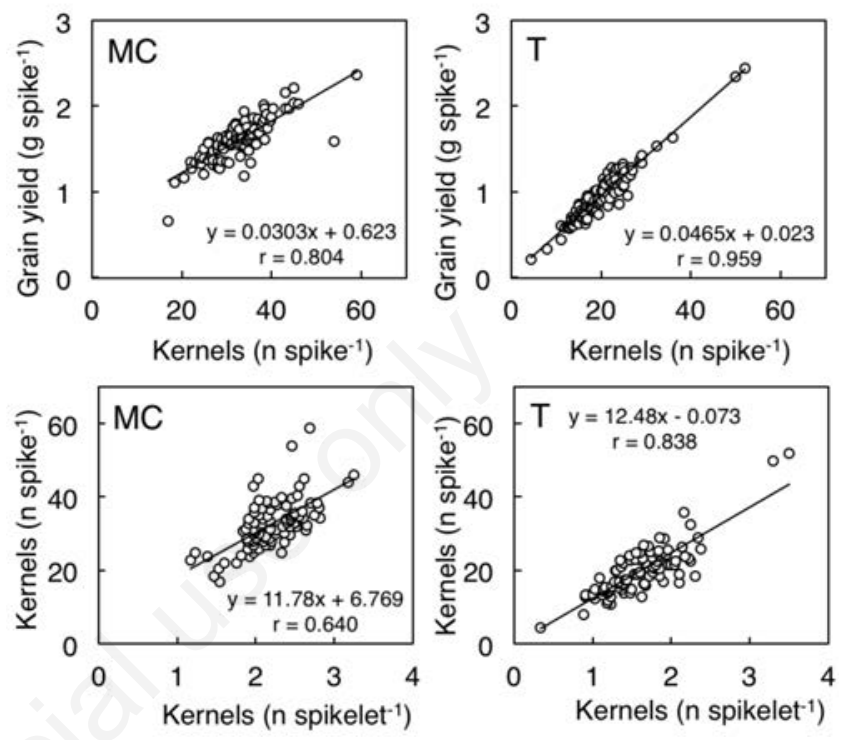

Figure 6. Relationship between grain yield per spike and kernels per spike, and between kernels per spike and kernels per spikelet, in main culms (MC) and tillers (T) $(n=96)$.

Table 7. Determinants of the numbers of spikelets and kernels in main culm and tiller spikes, as affected by the sowing date and cultivar mean effects.

\begin{tabular}{|c|c|c|c|c|c|}
\hline Treatment & $\begin{array}{l}\text { Initiated spikelets } \\
\left.\text { (n spike }{ }^{-1}\right)\end{array}$ & $\begin{array}{c}\text { Spikelet abortion } \\
(\%)\end{array}$ & $\begin{array}{l}\text { Fertile florets } \\
\text { (n spikelet }{ }^{-1} \text { ) } \\
\text { Main culm spike }\end{array}$ & $\begin{array}{l}\text { Grain recovery } \\
\text { per spikelet }(\%)\end{array}$ & $\begin{array}{l}\text { Fertile florets } \\
\text { (n spike }{ }^{-1} \text { ) }\end{array}$ \\
\hline \multicolumn{6}{|l|}{ Sowing date } \\
\hline November & $17.4^{\mathrm{a}}$ & $5.3^{\mathrm{a}}$ & $2.5^{\mathrm{b}}$ & $88.0^{\mathrm{a}}$ & $42.0^{\mathrm{a}}$ \\
\hline December & $15.1^{\mathrm{b}}$ & $2.5^{\mathrm{b}}$ & $2.7^{\mathrm{ab}}$ & $77.8^{\mathrm{b}}$ & $41.8^{\mathrm{a}}$ \\
\hline February & $13.9^{c}$ & $2.7^{\mathrm{b}}$ & $3.0^{\mathrm{a}}$ & $76.7^{\mathrm{b}}$ & $38.7^{\mathrm{a}}$ \\
\hline \multicolumn{6}{|l|}{ Cultivar } \\
\hline Claudio & $14.2^{\mathrm{b}}$ & $4.4^{\mathrm{a}}$ & $2.5^{\mathrm{b}}$ & $88.0^{\mathrm{a}}$ & $34.2^{\mathrm{b}}$ \\
\hline Normanno & $16.5^{\mathrm{a}}$ & $4.8^{\mathrm{a}}$ & $2.9^{\mathrm{a}}$ & $79.3^{\mathrm{b}}$ & $44.7^{\mathrm{a}}$ \\
\hline Saragolla & $17.3^{\mathrm{a}}$ & $0.3^{b}$ & $2.9^{\mathrm{a}}$ & $65.5 \mathrm{c}$ & $49.2^{\mathrm{a}}$ \\
\hline \multirow[t]{2}{*}{ Svevo } & $13.9^{\mathrm{b}}$ & $5.6^{\mathrm{a}}$ & $2.8^{\mathrm{a}}$ & $82.1^{\mathrm{a}}$ & $35.4^{\mathrm{b}}$ \\
\hline & & & Tiller spike & & \\
\hline \multicolumn{6}{|l|}{ Sowing date } \\
\hline November & $15.8^{\mathrm{a}}$ & $16.9^{\mathrm{a}}$ & $2.1^{\mathrm{a}}$ & $66.7^{\mathrm{a}}$ & $27.3^{\mathrm{a}}$ \\
\hline December & $12.8^{\mathrm{b}}$ & $9.5^{\mathrm{b}}$ & $2.2^{\mathrm{a}}$ & $63.6^{\mathrm{a}}$ & $28.3^{\mathrm{a}}$ \\
\hline February & $11.9^{\mathrm{b}}$ & $13.4^{\mathrm{ab}}$ & $2.3^{\mathrm{a}}$ & $60.9^{\mathrm{a}}$ & $23.8^{\mathrm{b}}$ \\
\hline \multicolumn{6}{|l|}{ Cultivar } \\
\hline Claudio & $12.7^{\mathrm{b}}$ & $13.2^{\mathrm{b}}$ & $2.1^{\mathrm{a}}$ & $57.1^{\mathrm{b}}$ & $22.6^{\mathrm{b}}$ \\
\hline Normanno & $15.0^{\mathrm{a}}$ & $17.3^{\mathrm{a}}$ & $2.3^{\mathrm{a}}$ & $60.9^{b}$ & $28.2^{\mathrm{a}}$ \\
\hline Saragolla & $14.2^{\mathrm{a}}$ & $7.9 \mathrm{c}$ & $2.2^{\mathrm{a}}$ & $59.1^{\mathrm{b}}$ & $28.1^{\mathrm{a}}$ \\
\hline Svevo & $12.1^{\mathrm{b}}$ & $15.7^{\mathrm{ab}}$ & $2.3^{\mathrm{a}}$ & $78.3^{\mathrm{a}}$ & $27.0^{\mathrm{a}}$ \\
\hline
\end{tabular}

Within each block, values followed by different letters are significantly different $(\mathrm{P}<0.05)$. 
florets per MC spikelet was 2.5 in Claudio compared to approximately 2.9 in the other cultivars, whereas in T spikelets it was not affected by sowing date and cultivar and was approximately 2.2 .

Grain recovery per spikelet, i.e., the proportion of fertile florets that actually produced kernels within each spikelet, was markedly higher in MC than in T spikes, at $80 v s 63 \%$ on average (Table 7). In $\mathrm{MC}$, grain recovery was significantly higher in the November sowing, whereas in $\mathrm{T}$ it was not affected by the sowing date. Grain recovery differed among varieties: in $\mathrm{MC}$ it ranked in the order Claudio $>$ Svevo $>$ Normanno $>$ Saragolla, whereas in $\mathrm{T}$ it was significantly higher in Svevo. Finally, grain recovery was significantly affected by spikelet position. In MC spikes it was $87 \%$ in the central spikelets and approximately $76 \%$ in the other positions, while in $\mathrm{T}$ spikes it was approximately $71 \%$ in the basal and central spikelets but only $47 \%$ in the terminal one (Figure 8 ).
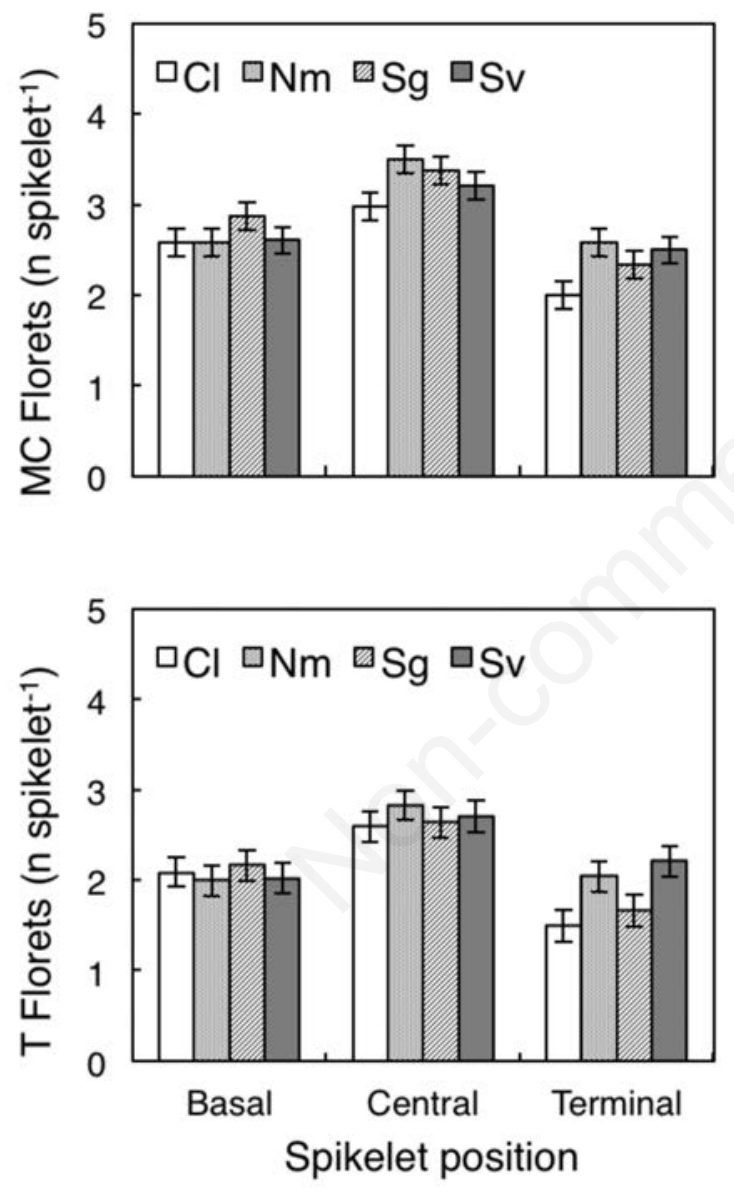

Figure 7. Number of florets per spikelet of main culm (MC) and tiller (T) spikes, as affected by cultivar and spikelet position within the spike. Cl, Claudio; Nm, Normanno, Sg, Saragolla; Sv, Svevo. Data are means of two years, three sowing dates and four replicates $(n=24)$. Vertical bars represent honest significant difference at $\mathbf{P}<\mathbf{0 . 0 5}$.
Table 8. Number of leaves and total primordia formed on the main culm apex, as affected by the sowing date and cultivar mean effects.

\begin{tabular}{lcc}
$\begin{array}{l}\text { Treatment } \\
\text { Leaves } \\
\text { Sowing date }\end{array}$ & $\begin{array}{c}\text { Total primordia } \\
\left.\text { (n apex }{ }^{-1}\right)\end{array}$ \\
November & $10.9^{\mathrm{a}}$ & $28.3^{\mathrm{a}}$ \\
December & $9.8^{\mathrm{b}}$ & $24.9^{\mathrm{b}}$ \\
February & $9.1^{\mathrm{c}}$ & $23.0^{\mathrm{b}}$ \\
Cultivar & & \\
Claudio & $10.8^{\mathrm{a}}$ & $25.0^{\mathrm{ab}}$ \\
Normanno & $9.8^{\mathrm{b}}$ & $26.3^{\mathrm{a}}$ \\
Saragolla & $9.3^{\mathrm{c}}$ & $26.6^{\mathrm{a}}$ \\
Svevo & $9.9^{\mathrm{b}}$ & $23.8^{\mathrm{b}}$ \\
\hline
\end{tabular}

Within each block, values followed by different letters are significantly different $(\mathrm{P}<0.05)$.
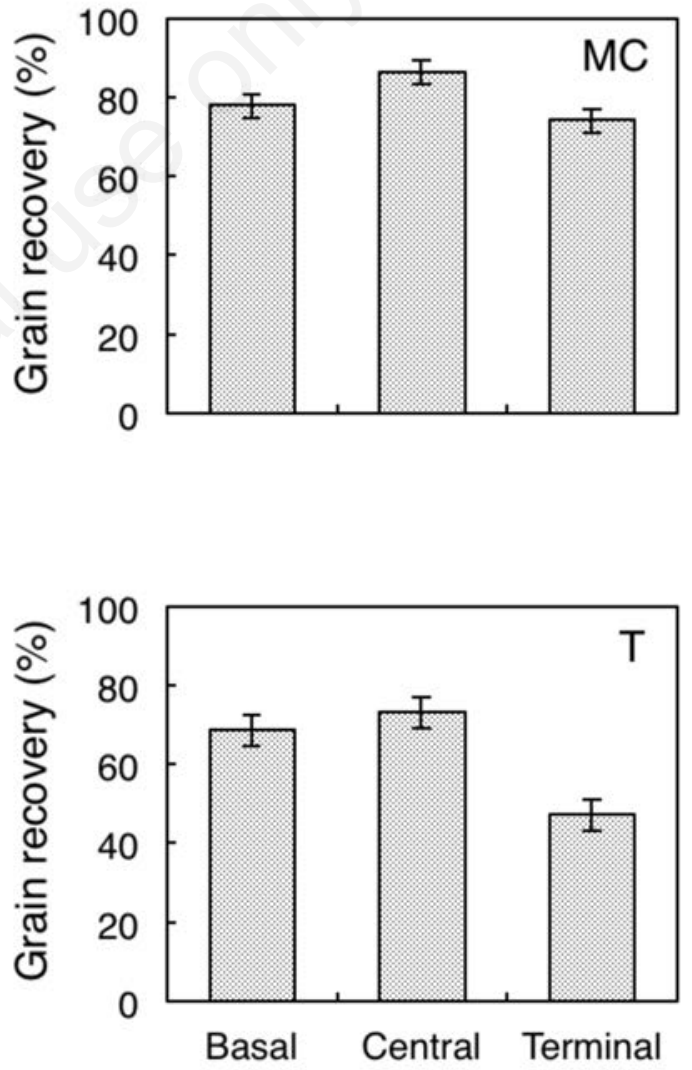

Figure 8. Grain recovery in spikelets of main culm (MC) and tiller (T) spikes, as affected by spikelet position within the spike. Data are means of two years, three sowing dates, four cultivars and four replicates $(n=96)$. Vertical bars represent honest significant difference at $\mathbf{P}<0.05$. 
The number of fertile florets per spike, estimated from the product of the average floret number of five sample spikelets and the number of complete spikelets per spike, was lower in February than in earlier sowings, but differences were significant only in $\mathrm{T}$ (Table 7). In MC spikes, the number of florets was approximately $30 \%$ higher in Saragolla and Normanno compared to Claudio and Svevo, whereas in T spikes it was approximately $20 \%$ lower in Claudio than in the other cultivars. Grain recovery calculated on spike basis showed patterns similar to those calculated for spikelets (data not reported).

\section{Discussion}

The durum wheat cultivars utilized in this research produced between 2.3 and $3.1 \mathrm{~g}$ of grain per plant. Between-years differences in grain yield were low compared to the marked differences in rainfall, probably because plants were grown in well-drained pots, which avoided waterlogging in 2012-2013, and also received artificial irrigation, which avoided drought stress up to anthesis in 2011-2012, and during grain filling in both years.

Variations in grain yield per plant were not significant between mid-autumn and winter sowings (November and December), while the delay to early spring (February) markedly decreased grain yield, primarily because of the lower tiller production, whereas the yield of single spikes did not, or only slightly, decreased. Yield decrease was less pronounced in Svevo, which was associated with the higher yield of tiller spikes compared to the other cultivars. The number of fertile tillers did not vary significantly among cultivars and, on average, the promoted good-tillering cv. Normanno and Svevo showed only 5\% higher yield compared to Claudio and Saragolla. These findings confirm that the plasticity in the number and yield of tiller spikes is crucial to responding positively to high yielding conditions (Sadras and Rebetzke, 2013; Slafer et al., 2014; Subira et al., 2015), and to compensate for the lower yield of main culm spikes (Elhani et al., 2007). They also highlight that the four tested cultivars perform similarly at stand densities ideal for good-tillering genotypes when grown in optimal water conditions (Valério et al., 2009).

Although tillers contributed substantially to grain yield, the average yield of one tiller spike was approximately half that of one main culm spike, which resulted from the sum of slightly lower spikelet initiation and higher spikelet abortion, on one hand, and a lower number of florets per spikelet, grain recovery and mean kernel weight, on the other.

\section{Effect of sowing date on spike yield components}

The delay of sowing markedly shortened the vegetative phase, which reduced the initiation of both leaf and spikelet primordia. Spikelet abortion also decreased, possibly because of lower intraspike competition, so that the reduction in the number of complete spikelets was less pronounced. According to Serrago et al. (2008), later sowings expose plants to a longer photoperiod during the phase of rapid stem elongation, thus reducing its duration and the number of fertile florets per spike. In contrast, we found that the thermal time of the period was only slightly affected and the number of florets per spikelet tended to increase, with a higher degree in main culm than in tiller spikes. Li et al. (2001) also reported that spikelet number was more sensitive to delays in sowing than floret production, which can be interpreted as an adjustment to the lower number of spikelets (Sinclair and Jamieson, 2006). We found, however, that excess florets were not fertilized, as shown by the lower grain recovery in later sowings, and, therefore, the number of kernels per spikelet was generally unaffected, and the number of kernels per spike decreased. It is worth noting that though floret production and grain recovery differed according to spikelet position, all spikelets responded similarly to sowing date, suggesting that they equally suffered from assimilates shortening in later sowings.

Mean kernel weight is the last-determined yield component, and thus it may compensate for the lower number of kernels produced in later sowings, provided that environmental conditions are favourable to ovary growth around anthesis and to grain filling later on (Moragues et al., 2006; Ferrise et al., 2010; Slafer et al., 2014). In many wheat growing areas, however, this does not occur because heat stress and terminal drought reduce grain growth duration and kernel weight (Brdar et al., 2008; Modarresi et al., 2010; Mitchell et al., 2013). In our research, grain-filling duration was not greatly affected and the thermal time was even longer in later sowings. The kernels were accordingly heavier in December and in February compared to November, but increments were not enough to compensate for the lower kernel number. Though our results could be influenced by the fact that the pots were irrigated, Khaledian et al. (2013) estimated that in the northern Mediterranean area, terminal growth is generally also maintained in rainfed field conditions.

In summary, delays from the conventional sowing date slightly decreased the yield of MC spikes, reducing primarily spikelet number, which was not compensated by higher production of florets per spikelet and only in part by increased kernel weight. As grain yield per plant did not differ significantly between November and December sowings, our results highlight that in the winter sowing, tillers fully compensated for the smaller MC spike by slightly increasing the number of fertile spikes per plant and by maintaining their size and grain set. Tillers thus play a key role in maintaining yield stability across autumn-winter sowings.

\section{Effect of genotype on spike yield components}

The four durum-wheat cultivars differed in the strategies of yield determination (Fischer, 2008), primarily in spike size, spikelet fertility, mean kernel weight, and in the contribution of tillers to yield, and also differed in the duration of phenological phases. Nevertheless, for all yield components, the response to sowing date showed similar patterns among cultivars, but differences in amplitude, so that a Cultivar $\times$ Sowing date interaction existed only for grain yield per plant.

Genotypic variation in response to the environment is often associated with differences in phenology (Miralles and Slafer, 2007; Modarresi et al., 2010; Borrás-Gelonch et al., 2012) and in our research it could depend on the wide variation in daylength sensitivity of durum wheat genotypes released in Italy (Motzo and Giunta, 2007; Subira et al., 2015). We found that cultivars differed in the relative length of vegetative, stem elongation and grain-filling phases, but, similar to the findings of Whitechurch et al. (2007), these differences tended to disappear in the winter and early spring sowings. Accordingly, differences in yield stability in late sowings cannot be ascribed to differences in the duration of phenological phases.

Tillering capacity is another trait associated with the responsiveness of genotypes to the environment (Dreccer et al., 2013; Sadras and Rebetzke, 2013; Hendriks et al., 2016). In our research, the cultivar Svevo exhibited the highest contribution of tillers to plant yield and the smallest yield loss in the February sowing, which relied on the elevated grain yield of single tiller spikes rather than on their number. Consistently, Slafer et al. (2014) reported 
that, while environment mainly drives variations in spike number, genotype drives those in kernels per spike. The good tiller yield was associated with higher grain recovery and mean kernel weight compared to those of other cultivars. Analysing the performances of Svevo against phenological and yield-component traits, we hypothesize that the higher yield stability depended on its more pronounced spring habit and very low sensitivity to daylength (Motzo and Giunta, 2007), which supported a faster initiation of both leaf and spikelet primordia and a higher growth rate of tillers (Arduini et al., 2010; Dreccer et al., 2013). This allowed Svevo to shorten the vegetative phase maintaining high leaf number and tiller yield (Borrás-Gelonch et al., 2012), and lengthen the stem elongation phase without delaying anthesis (Miralles and Slafer, 2007). Indeed, we found that both leaf number and tiller yield were higher in Svevo compared to the other early flowering cultivar Saragolla. In addition, because of the earlier start of stem elongation, Svevo formed overall less primordia (leaves + initiated spikelets) on the main culm compared to Saragolla, which probably reduced within and between spike competitions. These are both crucial for adequate floret development and fertilization (Bancal, 2009; González-Navarro et al., 2015). Our hypothesis is supported by the higher grain recovery and tiller contribution to yield in Svevo than in Saragolla, despite coincident anthesis, and according to Li et al. (2001), this can be consistent with the spring habit.

Conversely, the worse yield performance of the cultivar Claudio was primarily because of low spikelet fertility, which was due to lower floret production in both spike types, particularly in the central and upper spikelets, and to the lower grain recovery in tillers. We associated these traits with the longer vegetative phase, evidenced by the higher main-culm leaf number compared to other cultivars, and the short stem elongation phase, which reduces the time for floret differentiation and makes this cultivar similar to older genotypes (Motzo and Giunta, 2007; Álvaro et al., 2008). Ferrante et al. (2012) associated the lower yield of Claudio with lower grain set and fruiting efficiency. In our research, however, reduced spikelet fertility was in part compensated during grain filling, so that this cultivar showed the highest mean kernel weight.

The length of the entire growth cycle was equal in the four cultivars, so that earlier anthesis corresponded to longer grain filling. Accordingly, the latest flowering Normanno had the lowest mean kernel weight both in main culm and tillers, suggesting that late anthesis is detrimental to grain filling in Mediterranean photothermal conditions, independently of sowing time and despite an optimal water supply.

In line with the variability in spike size within Italian durum wheat germoplasm (De Vita et al., 2007; Álvaro et al., 2008), the four cultivars differed in spike size, Normanno and Saragolla showing larger spikes than Claudio and Svevo. In our research, larger main culm spikes produced more florets per spike, but suffered from intra-spike competition, as suggested by lower grain recovery and mean kernel weight. The higher yield of tiller spikes observed in Svevo compared to Normanno and Saragolla suggests that large main culm spikes are also more competitive for resources against tillers. In summary, we suggest that the higher yield stability of Svevo relies on the lowest difference in grain yield between main culm and tiller spikes, the former being the lowest yielding and the latter the highest.

Independent of sowing date and cultivar, the grain yield of both main culm and tiller spikes was closely related to the number of kernels per spike, but not to the mean kernel weight, which confirms compensation and less plasticity for the latter yield component (Slafer et al., 2014). In addition, we found that the number of kernels per spike was significantly and positively related to the number of kernels per spikelet, but not to the number of spikelets per spike, suggesting that lower spikelet numbers accommodate higher floret production and recovery.

\section{Conclusions}

We suggest that the question of whether tillers are a burden or a resource in durum wheat should be reconsidered. In fact, our results highlight that, at low plant density, tillers contributed at least $40 \%$ to plant yield and a better yield stability in later sowings was associated with a higher contribution of tillers to yield. We found that variations in tiller yield in response to sowing date depended primary on tiller number, whereas differences among cultivars relied on the yield of single tiller spikes. A Cultivar $\times$ Sowing date interaction was revealed for grain yield per plant, but not for the yield of main culm and tiller spikes and their components.

The analysis of spike types and their components showed that large main culm spikes are more competitive against tiller spikes, but also suffer from intra-spike competition and are more sensitive to delays in the sowing date. Therefore, we hypothesize that higher yield stability can be achieved with a more equal partitioning of resources within main culm and tillers, which can be obtained by reducing the number of main culm primordia and increasing their initiation rate. This allows for the stem elongation and grain filling phases to be longer without delaying anthesis, but it also reduces the sink strength of the main culm spike. Accordingly, more time and resources can be allocated to floret production and to grain fillingboth in main culm and tillers.

From a methodological point of view, our results show that the number of florets per spike can be effectively estimated by counting florets on only five spikelets from given positions: two basal, two central and the terminal spikelet.

\section{References}

Acevedo E, Silva P, Silva H, 2002. Wheat growth and physiology. In: BC Curtis, S Rajaram, H Gómez Macpherson (eds.) Bread Wheat Improvement and Production. FAO Plant Production and Protection Series, vol. 30. FAO, Rome, Italy, pp. 32.

Akhtar M, Ahmad N, Nasrullah M, Ali B, Zahid R, Shahid MI, 2012. Effect of late planting on emergence, tillering and yield of various varieties of wheat. J. Anim. Plant Sci. 22:1163-6.

Álvaro F, Isidro J, Villegas D, García del Moral LF, Royo C, 2008. Old and modern durum wheat varieties from Italy and Spain differ in main spike components. Field Crop. Res. 106:86-93.

Arduini I, Ercoli L, Mariotti M, Masoni A, 2009. Sowing date affect spikelet number and grain yield of durum wheat. Cereal Res. Commun. 37:469-78.

Arduini I, Ercoli L, Mariotti M, Masoni A, 2010. Coordination between plant and apex development in Hordeum vulgare spp. distichum. CR Biol. 333:454-60.

Bancal P, 2009. Early development and enlargement of wheat floret primordia suggest a role of partitioning within spike to grain set. Field Crop. Res. 110:44-53.

Bassu S, Asseng S, Motzo R, Giunta F, 2009. Optimising sowing date of durum wheat in a variable Mediterranean environment. Field Crop. Res. 111:109-18.

Bassu S, Giunta F, Motzo R, 2010. Effects of sowing date and cul- 
tivar on spike weight and kernel number in durum wheat. Crop Pasture Sci. 61:287-95.

Borrás-Gelonch G, Rebetzke GJ, Richards RA, Romagosa I, 2012. Genetic control of duration of pre-anthesis phases in wheat (Triticum aestivum L.) and relationships to leaf appearance, tillering, and dry matter accumulation. J. Exp. Bot. 63:69-89.

Brdar MD, Kraljević-Balalić MM, Kobiljski BD, 2008. The parameters of grain filling and yield components in common wheat (Triticum aestivum L.) and durum wheat (Triticum turgidum L. var. durum). Cent. Eur. J. Biol. 3:75-82.

De Vita P, Li Destri Nicosia O, Nigro F, Platani C, Riefolo C, Di Fonzo N, Cattivelli L, 2007. Breeding progress in morphophysiological, agronomica land qualitative traits of durum wheat cultivars released in Italy during the $20^{\text {th }}$ century. Eur. J. Agron. 26:39-53.

Dreccer MF, Chapman SC, Rattey AR, Neal J, Song Y, Christopher $\mathrm{J}(\mathrm{J}) \mathrm{T}$, Reynolds M, 2013. Developmental and growth controls of tillering and water-soluble carbohydrate accumulation in contrasting wheat (Triticum aestivum L.) genotypes: can we dissect them? J. Exp. Bot. 64:143-60.

Elhani S, Martos V, Rharrabti Y, Royo C, García del Moral LF, 2007. Contribution of main stem and tillers to durum wheat (Triticum turgidum L. var. durum) grain yield and its components grown in Mediterranean environments. Field Crop. Res. 103:25-35.

Ercoli L, Lulli L, Arduini I, Mariotti M, Masoni A, 2011. Durum wheat grain yield and quality as affected by $\mathrm{S}$ rate under Mediterranean conditions. Eur. J. Agron. 35:63-70.

Ercoli L, Masoni A, Pampana S, Mariotti M, Arduini I, 2013. As durum wheat productivity is affected by nitrogen fertilisation management in Central Italy. Eur. J. Agron. 44:38-45.

Ercoli L, Masoni A, Pampana S, Mariotti M, Arduini I, 2014. The response of durum wheat to the preceding crop in a Mediterranean environment. Sci. World J. 2014:717562.

Eshaghi L, Pouryousef M, Kamkar B, 2011. Quantification of stem elongation rate in response to temperature and photoperiod by 24 multiplicative models. Int. J. Plant Dev. Biol. 5:67-72.

Ferrante A, Savin R, Slafer GA, 2012. Differences in yield physiology between modern, well adapted durum wheat cultivars grown under contrasting conditions. Field Crop. Res. 136:52-64.

Ferrise R, Triossi A, Stratonovich P, Bindi M, Martre P, 2010. Sowing date and nitrogen fertilisation effects on dry matter and nitrogen dynamics for durum wheat: An experimental and simulation study. Field Crop. Res.117:245-57.

Fischer RA, 2008. The importance of grain or kernel number in wheat: a reply to Sinclair and Jamieson. Field Crop. Res. 105:15-21.

Fischer RA, 2016. The effect of duration of the vegetative phase in irrigated semi-dwarf spring wheat on phenology, growth and potential yield across sowing dates at low latitude. Field Crop. Res. 198:188-99.

González-Navarro OE, Griffiths S, Molero G, Reynolds MP, Slafer GA, 2015. Dynamics of floret development determining differences in spike fertility in an elite population of wheat. Field Crop. Res. 172:21-31.

Guo Z, Schnurbusch T, 2015. Variation of floret fertility in hexaploid wheat revealed by tiller removal. J. Exp. Bot. 66:5945-58.

Hendriks PW, Kirkegaard JA, Lilley JM, Gregory PJ, Rebetzke GJ, 2016. A tillering inhibition gene influences root-shoot carbon partitioning and pattern of water use to improve wheat productivity in rainfed environments. J. Exp. Bot. 67:327-40.
Inagaki MN, Valkoun J, Nachit MM, 2007. Effect of soil water deficit on grain yield in synthetic bread wheat derivatives. Cereal Res. Commun. 35:1603-8.

Kebrom TH, Chandler PM, Swain SM, King RW, Richards RA, Spielmeyer W, 2012. Inhibition of tiller bud outgrowth in the tin mutant of wheat is associated with precocious internode development. Plant Physiol. 160:308-18.

Khaledian MR, Mailhol JC, Ruelle P, Dejean C, 2013. Effect of cropping strategies on the irrigation water productivity of winter wheat. Plant Soil Environ. 59:29-36.

Kumar PV, Rao VUM, Bhavani O, Dubey AP, Singh CB, 2016. Effect of temperature and photothermal quotient on the yield components of wheat (Triticum aestivum L.) in Indo-Gangetic plains of India. Exp. Agr. 52:14-35.

Li C, Cao W, Dai T, 2001. Dynamic characteristics of floret primordium development in wheat. Field Crop. Res. 71:71-6.

Mahdi L, Bell CJ, Ryan J, 1999. Establishment and yield of wheat (Triticum turgidum L.) after early sowing at various depths in a semi-arid Mediterranean environment. Field Crop. Res. 58:187-96.

McMaster GS, Wilhelm WW, 1997. Growing degree-days: one equation, two interpretations. Agr. Forest Meteorol. 87:291-300.

Miralles DJ, Slafer GA, 2007. Sink limitations to yield in wheat: how could it be reduced? J. Agr. Sci. 145:139-49.

Mitchell JH, Rebetzke GJ, Chapman SC, Fukai S, 2013. Evaluation of reduced-tillering (tin) wheat lines in managed, terminal water deficit environments. J. Exp. Bot. 64:3439-51.

Modarresi M, Mohammadi V, Zali A, Mardi M, 2010. Response of wheat yield related traits to high temperature. Cereal Res. Commun. 38:23-31.

Moragues M, García del Moral LF, Moralejo M, Royo C, 2006. Yield formation strategies of durum wheat landraces with distinct pattern of dispersal within the Mediterranean basin I: Yield components. Field Crop. Res. 95:194-205.

Motzo R, Giunta F, 2007. The effect of breeding on the phenologyof Italian durum wheats: from landraces to modern cultivars. Eur. J. Agron. 26:462-70.

Porter JR, Gawith M, 1999. Temperatures and the growth and development of wheat: a review. Eur. J. Agron. 10:23-36.

Rharrabti Y, Miralles DJ, Martos V, García del Moral LF, 2010. Grain weight of durum wheat cultivars released in Italy and Spain during the $20^{\text {th }}$ century as affected by source-sink manipulations. Cereal Res. Commun. 38:134-45.

Sadras VO, Rebetzke GJ, 2013. Plasticity of wheat grain yield is associated in plasticity of ear number. Crop Pasture Sci. 64:234-43.

Serrago RA, Miralles DJ, Slafer GA, 2008. Floret fertility in wheat as affected by photoperiod during stem elongation and removal of spikelets at booting. Eur. J. Agron. 28:301-8.

Sinclair TR, Jamieson PD, 2006. Grain number, wheat yield, and bottling beer: An analysis. Field Crop. Res. 98:60-7.

Slafer GA, Savin R, Sadras VO, 2014. Coarse and fine regulation of wheat yield components in response to genotype and environment. Field Crop. Res. 157:71-83.

Spink JH, Semere T, Sparkes DL, Wahley JM, Foulkes MJ, Clare RW, Scott RK, 2000. Effect of sowing date on the optimum plant density of winter wheat. Ann. Appl. Biol. 137:179-88.

Steel RGD, Torrie JH, Dickey DA, 1997. Principles and procedure of statistics: a biometrical approach. McGraw Hill, New York, USA.

Subira J, Álvaro F, García del Moral LF, Royo C, 2015. Breeding effects on the cultivar $\mathrm{x}$ environment interaction of durum wheat yield. Eur. J. Agron. 68:78-88. 
Trnka M, Rötter RP, Ruiz-Ramos M, Kersebaum KC, Olesen JE, Žalud Z, Semenov MA, 2014. Adverse weather conditions for European wheat production will become more frequent with climate change. Nat. Clim. Change 4:637-43.

Uzik M, Zofajova A, 2007. Translocation of dry matter in ten winter wheat cultivars released in the years 1921-2003. Cereal Res. Commun. 35:1583-92.

Valério IP, Félix de Carvalho FI, Costa de Oliveira A, Benin G, Queiroz de Sousa V, de Almeida Machado A, Bertan I, Cardoso Busato C, da Silveira G, Fonseca DAR, 2009.
Seeding density in wheat genotypes as a function of tillering potential. Sci. Agr. 66:28-39.

Whitechurch EM, Slafer GA, Miralles DJ, 2007. Variability in the duration of stem elongation in wheat and barley genotypes. J. Agr. Crop Sci. 193:138-45.

Xie Q, Mayes S, Sparkes DL, 2016. Optimizing tiller production and survival for grain yield improvement in a bread wheat $\mathrm{x}$ spelt mapping population. Ann. Bot. 117:51-66.

Zadoks JC, Chang TT, Konzak CF, 1974. A decimal code for the growth stages of cereals. Weed Res. 14:415-21. 